УДК 621.165-225:519.872.8

doi: 10.32620/aktt.2021.4sup2.05

А. Г. ЖИРКОВ ${ }^{1}$, А. П. УСАТЫЙ ${ }^{2}$ Е. П. АВДЕЕВА ${ }^{2}$ Ю. И. ТОРБА ${ }^{1}$

${ }^{1}$ ГП «Ивченко-Прогресс», Запорожнье, Украина

${ }^{2}$ Национальный технический университет «Харьковский политехнический институт», Харьков, Украина

\title{
СТРУКТУРА ПОТОКА В МЕЖЛОПАТОЧНОМ КАНАЛЕ СОПЛОВОГО АППАРАТА С ПОВОРОТНОЙ ДИАФРАГМОЙ
}

\begin{abstract}
В проиессе разработки метода численного исследования плоского обтекания сопловой решетки с поворотной диафрагмой были выполнены расчеты при различных степенях открытия поворотной диафрагмы $\delta$ и перепадах давлений получены сложные картины течения, в межлопаточном канале соплового аппарата. В статье приведены некоторые результаты численного исследования сверхзвукового течения в канале соплового аппарата при степени открытия поворотной диафрагмы $\delta=(0,15 \div 0,3)$. Моделирование и расчет течения рабочего тела выполнено с использованием программного комплекса Fluent. Проведено построение расчетных областей, ограниченных одним межслопаточным каналом, для разной степени открытия диафрагмы соплового аппарата. Построены сетки для расчетных областей. Проведены расчеты для $\delta=(0,15 \div 0,3)$ и при различных степенях перепада давления на решетке. В результате выполненных расчетов были получены картины течения в межслопаточном канале и за ним, и распределение коэффициентов потери кинетической энергии по фронту решетки при различных степенях открытия диафрагмы на входе в сопловой аппарат. По результатам проведенной работы можно сделать следующчие выводы: структура потока в межлопаточном канале, соплового аппарата при мальх степенях открытия, разделена на две части: сверхзвуковое ядро у корытиа лопатки и дозвуковую, вихревую зону у спинки лопатки; сверхзвуковое ядро потока при определенных значениях относительного перепада давлений на решетке (или величины расхода воздуха через решетку) разделяется ударными фронтами на несколько областей; коэффициенты потерь энергии, для мальх степеней открытия, уменьшаются при уменьшении относительных перепадов давления (при увеличении скорости истечения потока из сопловой решетки);наибольший вклад в величину потерь кинетической энергии вносит вихревая зона в межлопаточном канале, а не волновые явления в ядре потока; оптимизачию проточной части соплового аппарата необходимо проводить с целью уменьшения областей с вихревым течением. Результаты, полученные в данной работе, будут использованы для разработки методики численного исследования пространственного обтекания сопловых решеток с поворотными диафрагмами.
\end{abstract}

Ключевые слова: поворотная диафрагма; численное исследование; коэффициенты потерь энергии; теплофикачионные турбины; модели турбулентности.

\section{Введение}

Постоянное развитие и совершенствование конструкции и рабочих режимов теплофикационных турбин привело к использованию пара с сверхкритическими параметрами. На данный момент времени одним из перспективных направлений развития теплофикационных турбин является их работа на супер сверхкритических перепадах давления [1]. Повышение параметров пара влечет за собой повышение скоростей потока в межлопаточных каналах сопловых и рабочих каналах. При этом необходимо перепрофилирование проточной части для получения оптимальной геометрии с наименьшими коэффициентами потери кинетической энергии. Разработка методов оптимизации проточной части теплофикационных турбин является актуальной задачей [2].

Исследованиям трансзвуковых и сверхзвуковых течений в каналах посвящено большое количество работ, например, [3 - 6]. Но особенностью теплофикационных турбин, имеющих регулируемые отборы пара, является применение сопловых реше- ток с поворотными диафрагмами. [7]. Изменение расхода пара через турбину при переменных режимах достигается перекрытием, на входе, каналов соплового аппарата. Часть соплового аппарата, что перекрывает канал на входе, называется поворотной диафрагмой.

На структуру течения в канале сопловой решетки большое влияние оказывает степень открытия диафрагмы $\delta$ [8]. Здесь $\delta$ - степень открытия поворотной диафрагмы - отношение площади прикрытой поворотной диафрагмы а к площади полностью открытой диафрагмы а 0 . В процессе разработки метода численного исследования плоского обтекания сопловой решетки с поворотной диафрагмой были выполнены расчеты при различных степенях открытия поворотной диафрагмы $\delta$ и перепадах давлений $\pi$ на решетке. В результате расчетов, для малых степеней открытия поворотной диафрагмы, были получены сложные картины течения, в межлопаточном канале соплового аппарата, с делением ядра потока на сверхзвуковые области, представленные на рис. 1

(C) А. Г. Жирков, А. П. Усатый, Е. П. Авдеева, Ю. И. Торба, 2021 


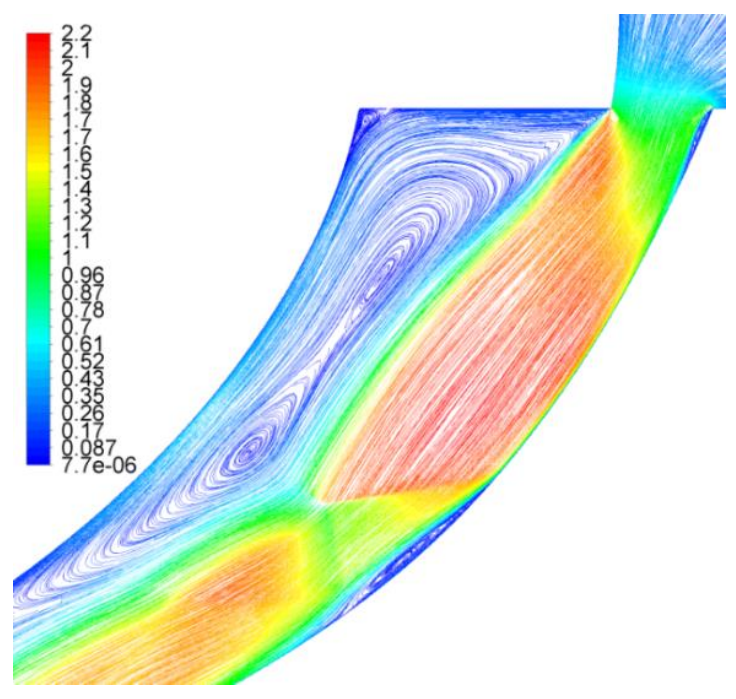

Рис. 1. Течение в расчетной области.

Изолинии чисел Маха при $\pi=0,3 \delta=0,3$

Для более детального исследования этих явлений проведено дополнительное численное исследование. В работе приведены некоторые результаты численного исследования сверхзвукового течения в канале соплового аппарата при степени открытия поворотной диафрагмы $\delta=(0,15 \div 0,3)$.

Численные исследования проводились с использованием программного комплекса Fluent.

\section{1. Сетка в расчетной области}

Расчетная область представляет собой один межлопаточный канал, образованный спинкой и корытцем профиля С-9013Р разработки МЭИ [9] (рис. 2).

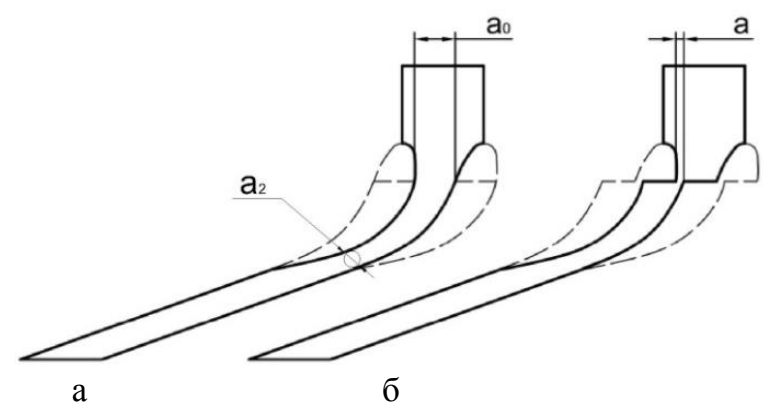

Рис. 2. Расчетная область для профиля С-9013Р при $\delta=1$ (а) и $\delta=0,15$ (б)

Основное требование к расчетной сетке - качественное разрешение физических явлений, имеющих место в расчетной области [10]. С одной стороны, сетка должна обеспечивать разрешение явлений в пограничном слое пристеночной области и явлений в проточной части решетки, и за ее пределами, возникающих при трансзвуковых и сверхзвуковых скоростях течениях потока (скачки уплотнения, отрывы потока, следы). Что требует уплотнения сетки в указанных областях. С другой - размер ячеек сетки должен быть ограничен с точки зрения времени, затрачиваемого на проведение вычислений.

Учитывая все выше сказанное, при построении сетки в расчетной области, был применён следующий подход. Так как положение, в канале и за ним, скачков уплотнений, отрывов потока и прочего неизвестно, то сетка строилась для обеспечения условия $\mathrm{y}^{+} \approx 1$ в пристеночной области.

Толщина пограничного слоя разбивалась на 25 подслоев, с коэффициентом увеличения элементов 1,2. Размер остальной сетки устанавливался равным размеру ячейки в последнем подслое.

В результате число элементов сетки составляло от $1,8 \cdot 10^{5}$ до $2,4 \cdot 10^{5}$ в зависимости от степени открытия $\delta$.

\section{2. Численное исследование}

После получения расчетом картины течения, представленной на рис. 1, были выполнены проверки результатов расчета:

1. Проведено численное исследование течения в межлопаточном канале решетки профилей С-9013Р при $\pi=0,3$ и $\delta=0,3$ с использованием модели турбулентности Reynolds Stress. Модель применяется для моделирования турбулентности и позволяет получать хорошее совпадение результатов расчета сверхзвуковых струйных течений с результатами эксперимента [11]. Так как в модели используются пристеночные функции, для разрешения явлений в пограничном слое, была построена отдельная расчетная область с сеткой удовлетворяющей условию $\mathrm{y}^{+} \leq 30$ с количеством элементов $\approx 63000$ шт.

На рис. 3 представлена картина течения, полученные при расчете с использованием модели турбулентности Reynolds Stress. Как видно из рисунка характер течения, в межлопаточном канале, полученный расчетом с использованием модели турбулентности Reynolds Stress схож с ранее полученной картиной течения, рассчитанной с использованием модели турбулентности k- $\omega$ SST (см. рис. 1).

2. Произведено численное исследование пространственного течения в межлопаточном канале. Для чего выполнено моделирование межлопаточного канала соплового аппарата со степенью открытия диафрагмы $\delta=0,3$ для расчета пространственного течения. Высота канала составила 80 мм. В расчетной области построена сетка из Poly-Hexcore элементов (технология Mosaic ${ }^{\mathrm{TM}}$, которая позволяет строить сетку, состоящую из гексагональных призм в пристеночной области и осуществлять прямой переход от полиэдрической сетки к гексаэдрической минуя тетра-ячейки). 


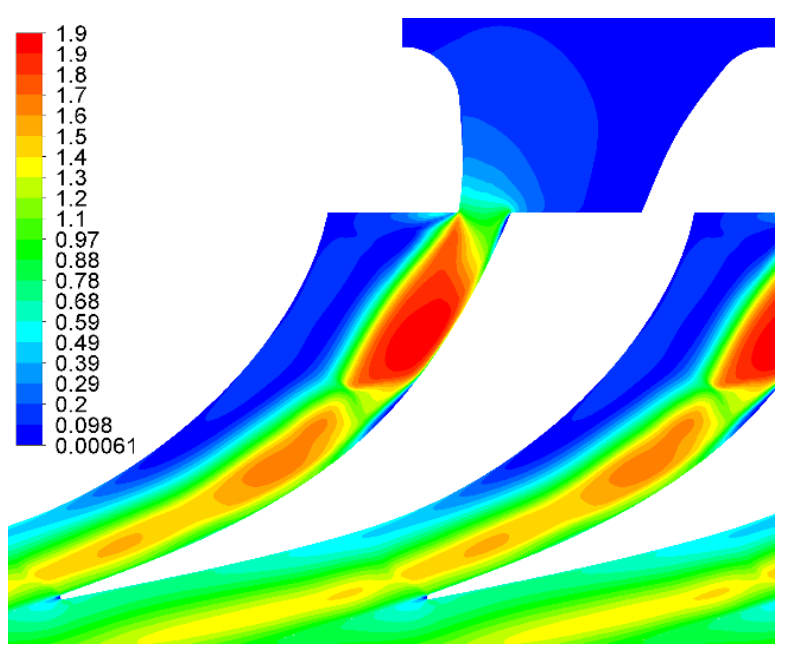

Рис. 3. Течение в расчетной области.

Изолинии чисел Маха при $\pi=0,3 \delta=0,3$, модель турбулентности Reynolds Stress

Так как основной задачей было подтверждение ранее полученной картины течения в межлопаточном канале, без расчета коэффициентов потери кинетической энергии, то расчетная область была разбита на относительно небольшое количество элементов - немногим более 8 миллионов. Все настройки решателя такие же, как и при моделировании плоского течения, использовалась модель

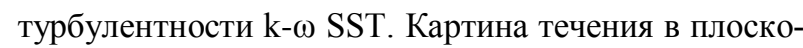
сти на высоте 40 мм представлена на рис. 4.

Во всех трех случаях проверочного расчета была получена картина течения в межлопаточном канале с делением ядра потока на сверхзвуковые области. На основе этого был сделан вывод о возможном присутствии подобных явлений в реальном сопловом аппарате и принято решение о проведении дополнительного исследования течения в межлопаточном канале соплового аппарата с поворотной диафрагмой при малых степенях открытия.

Для численного исследования плоского течения использовалась модель двумерного течения вязкого газа CFD-решателя Fluent с использованием разностного метода второго порядка.

Рабочее тело - вязкий сжимаемый газ - воздух. Для расчета явлений турбулентности использовалась модель турбулентности k- $\omega$ SST (модель Ментера) [12]. В качестве граничных условий на входе в расчетную область использовались:

- давление и температура воздуха, для некоторой части расчетов расход и температура воздуха;

- направление потока воздуха;

- интенсивность турбулентности;

- гидравлический диаметр.

Граничным условием на выходе из расчетной области задавалось давление воздуха.

Все расчеты выполнялись в два этапа.

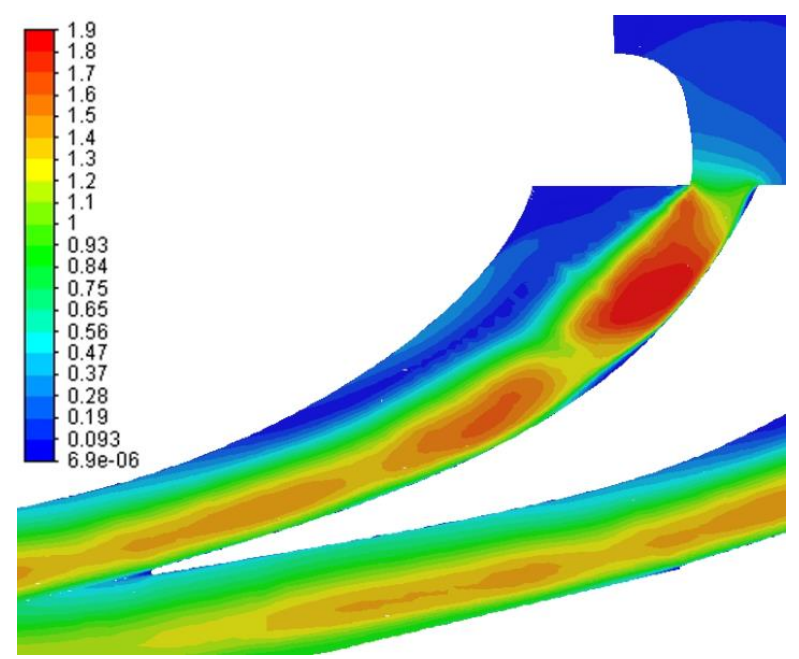

Рис. 4. Течение в расчетной области.

Изолинии чисел Маха при $\pi=0,3 \delta=0,3$

Выполнялся «черной» расчет течения, с использованием утилиты FMG. Утилита FMG использует технологию ANSYS FLUENT FAS Multigrid позволяющую выполнить расчет на наборе последовательно вложенных сеток. Расчет начинается на наиболее грубой сетке и по мере его установления результаты интерполируются на следующую, более мелкую, сетку. Как правило, все «черновые» расчеты, для достижения величин невязок $10^{-6}$, требовали не более $1000 \div 2000$ итераций. По результатам «чернового» расчета производилась адаптация сетки в местах больших градиентов расчетных параметров и для обеспечения условия $\mathrm{y}^{+} \leq 1$. В результате адаптации получалась сетка с подвешенными узлами.

Для «чистовых» расчетов, в зависимости от величин М и $\delta$, величина итераций составляла $20000 \div 33000$ шт. Сходимость расчета оценивалась по установлению равенства расходов на входе и выходе из расчетной области и по установлению невязок коэффициента потерь кинетической энергии.

\section{3. Результаты расчетов}

Для применения одной из теорий, описывающих явления при сверхзвуковом течении, необходимо решить вопрос о типе течения в межлопаточном канале. С одной стороны, несомненно, это сверхзвуковое течение в поворачивающем канале, с другой, из-за внезапного расширения после поворотной диафрагмы, часть течения можно рассматривать как истечение сверхзвуковой струи в полость с давлением практически равному давлению в струе.

Также можно выделить два режима течения в расчетной области. При первом минимальная площадь находится в горле $\mathrm{a}_{2}$ межлопаточного канала (см. рис. 2) - конфузорное течение в канале. Во вто- 
ром случае, при малых степенях открытия $\delta$ когда отношение $\tau$ ширины канала на входе а к горлу решетки $\mathrm{a}_{2}$ становится меньше единицы - диффузорное течение в канале.

На рис. 5 представлена зависимость отношения расходов от отношения $\tau$ ширины канала на входе а к горлу решетки $\mathrm{a}_{2}$.

Как видно из графика (см. рис. 5) дросселированние потока начинает происходить при значениях $\tau>1$. Так при $\tau=1,7$ отношение расходов через сопловой аппарат $\mathrm{G} / \mathrm{G}_{0}=0,99$; при $\tau=1,4$ отношение $\mathrm{G} / \mathrm{G}_{0}=0,97$ и т.д. При этом отношение расходов через сопловой аппарат $\mathrm{G} / \mathrm{G}_{0} \mathrm{He}$ зависит от перепада давлений $\pi$ на решетке для одинаковых значений $\tau(\delta)$.

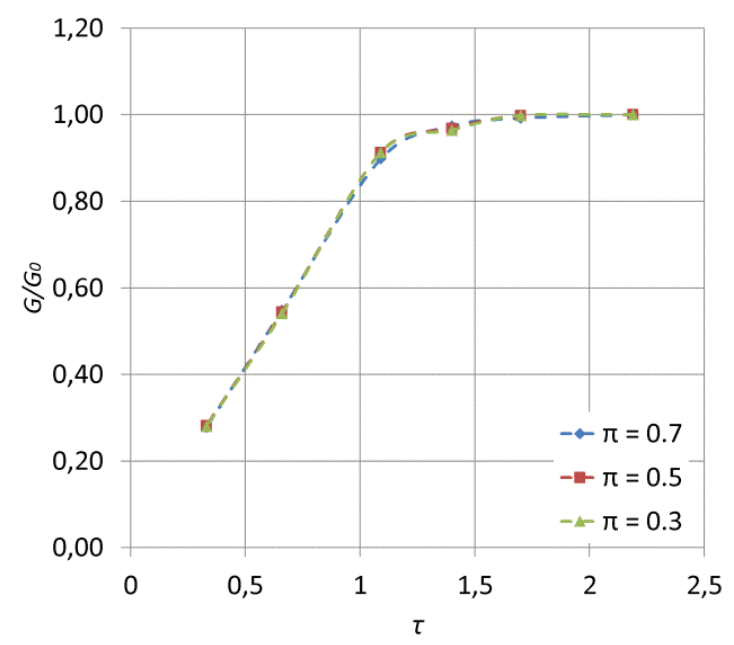

Рис. 5. Зависимость отношения расходов воздуха через сопловой аппарат G / G0 от $\tau$

На рис. 6 представлены расчётные изолинии чисел Маха для исследуемой решетки профилей $\mathrm{C}-9013$ Р при $\pi=0,3$ и $\delta=0,3$ с указанием номеров и положений сечений измерения распределений статического давления по межлопаточному каналу.

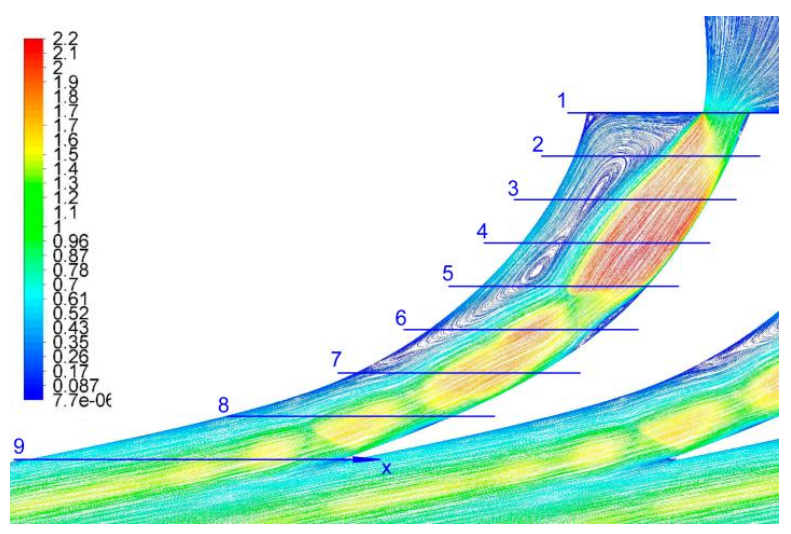

Рис. 6. Течение в расчетной области при $\pi=0,3$ и $\delta=0,3$ Изолинии чисел Маха и положение сечений измерения статического давления
Так как должно соблюдаться условие равенства расходов на входе и выходе из решетки, то при диффузорном течении, в канале происходит местное увеличение скорости в ядре потока для компенсации уменьшения площади проходного сечения из-за перекрытия поворотной диафрагмы. Как видно из рис. 7 статическое давление на выходе из канала (сечения 8,9 ) имеет большую величину, чем на входе в канал (сечения 2, 3).

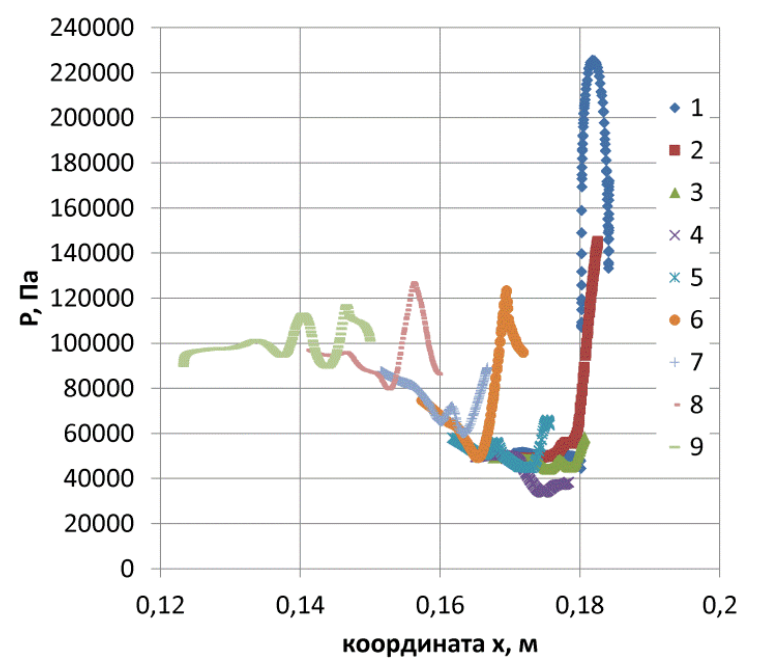

Рис. 7. Распределение величин статического давления вдоль межлопаточного канала при $\pi=0,3$ и $\delta=0,3$

То есть движение потока происходит против положительного градиента давления. При этом межлопаточный канал разделен на две области: у корытца лопатки область сверхзвукового течения, у спинки область вихревого, дозвукового течения.

Для упрощения описания явлений в канале обозначим области течений (рис. 8).

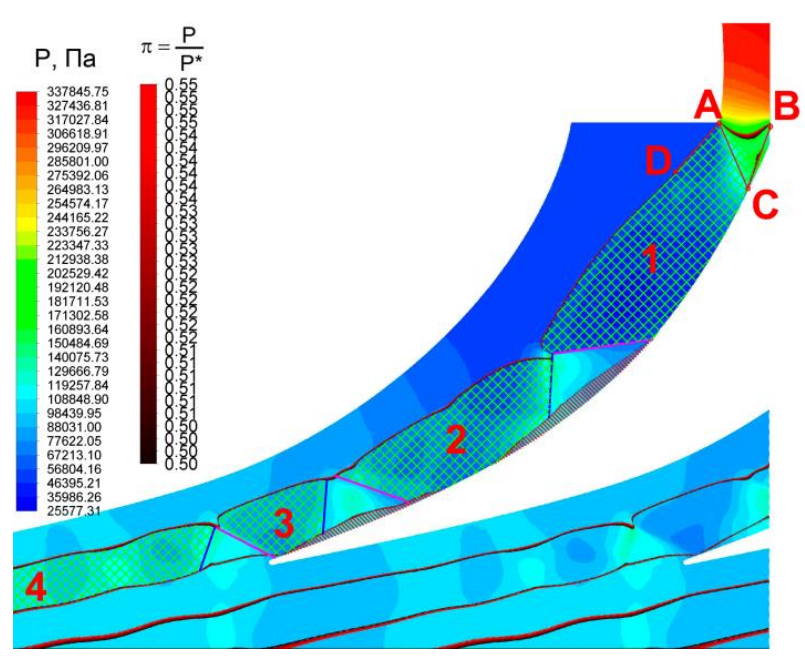

Рис. 8. Области течений в межлопаточном канале при $\pi=0,3$ и $\delta=0,3$ 
После прохождения потоком поворотной диафрагмы течение в треугольнике $\mathrm{ABC}$ происходит подобно течению в косом срезе соплового аппарата. Так как давление перед поворотной диафрагмой больше, чем за ней (см. рис. 7), то расширение газа происходит в косом срезе $\mathrm{ABC}$, который играет, таким образом, роль расширяющейся части сопла.

Процесс расширения газа в косом срезе заключается в следующем. Поскольку давление постепен-

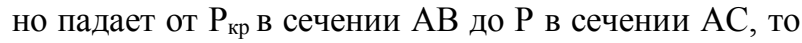
изобары, соответствующие промежуточным давлениям, располагаются приблизительно в виде лучей, исходящих из точки А. Таким образом, на участке ВС давление уменьшается постепенно, в то время как в точке А давление падает мгновенно от $\mathrm{P}_{\text {кр }}$ до $\mathrm{P}$, а следовательно, и вдоль линии $\mathrm{AD}$ являющейся границей струи, давление будет равно Р. Под влиянием этой разницы давлений на границе струи появляется результирующая сила, направленная перпендикулярно оси канала, которая поворачивает поток на некоторый угол. В результате этого поворота ширина струи увеличивается, получается расширяющееся сопло, обладающее возможностью сработать сверхкритический перепад давлений [13]. Что и происходит в области 1. Далее, так как движение потока происходит против положительного градиента давлений, то есть величина давления в потоке должна постепенно стать равной величине давления за сопловым аппаратом, возникает ударный фронт (показан розовой линией) представляющий собой волну сжатия, давление и плотность газа в ней увеличиваются. Ударный фронт начинается на стенке, наклонно к ней, и сопровождается отрывом струи от корытца лопатки (отрывы показаны штриховкой красного цвета). Дойдя до границы струи ударный фронт, отражается от неё и возникает отраженный фронт (показан синей линией). При этом отраженный ударный фронт является волной разряжения, и граница струи снова расходится. Затем весь процесс повторяется - области 2 и 3 . Действием вязкости на границе струи эта периодическая картина, в конце концов, стирается - область $4[13,14]$.

С целью определения величины относительного перепада давлений на сопловом аппарате, при котором происходит деление ядра потока ударными фронтами на отдельные области, представленные на рис. 8, выполнены дополнительные расчеты при относительных перепадах давления на сопловой решетке $\pi=0,5 ; 0,45 ; 0,4 ; 0,35 ; 0,3$. В результате выполненных расчетов было установлено, что для степени открытия $\delta=0,3 \quad(\tau=0,66)$ деление ядра потока области ударными фронтами на области начинает происходить при относительном перепаде $\pi=0,4$.
Реальные сопловые аппараты с поворотными диафрагмами, работают с отборами пара, что происходят в полости перед сопловым аппаратом. Подтверждено существенное влияние на характер процессов в проточной части турбины, эффективность сопловых решеток регулируемых поворотных диафрагм и их ступеней, а также на интегральные показатели качества всей турбины уровней давления в камерах регулируемых отборов и величин массовых расходов обираемого пара. В связи, с чем выполнено численное исследование влияния величины отбора воздуха на характер течения и потери кинетической энергии в решетке. Расчеты проведены для величин отборов $\mathrm{G} / \mathrm{G}_{0}=1 ; 0,75 ; 0,6875 ; 0,625 ; 0,5$ при степенях открытия поворотной диафрагмы $\delta=0,3$; при $\pi=0,3$. На рис. 9 представлена зависимость коэффициента потерь кинетической энергии в сопловой решетке от величины отбора воздуха. Как видно из графика, потери возрастают при увеличении отбора воздуха перед сопловым аппаратом.

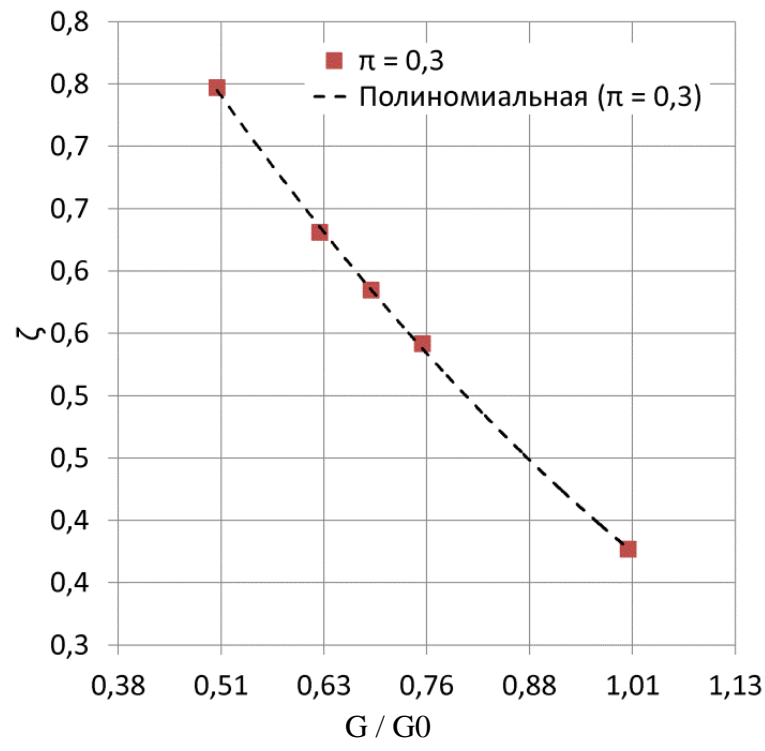

Рис. 9. Зависимость коэффициента потерь кинетической энергии от величины отборов G / G0

При уменьшении величины оборов воздуха перед сопловым аппаратом картина течения изменяется подобно как при уменьшении относительного перепада давлений $\pi$. Деление ядра потока ударными фронтами на отдельные области начинается при отношении $\mathrm{G} / \mathrm{G}_{0}=0,6875$.

На рис. 10 представлено распределение коэффициентов потери кинетической энергии вдоль фронта решетки при степени открытия поворотной диафрагмы $\delta=0,3$ при разных относительных перепадах давления на решетке.

Анализ графика указывает, что потери кинетической энергии уменьшаются при увеличении ско- 
рости потока, то есть при меньших относительных перепадах $\pi$. В относительных величинах коэффициент потери кинетической энергии в решетке на $22,5 \%$ больше при $\pi=0,7$, чем при $\pi=0,3$.

На рис. 11 представлены изолинии чисел Маха в межлопаточном канале при $\pi=0,7 ; 0,3$ и $\delta=0,3$.

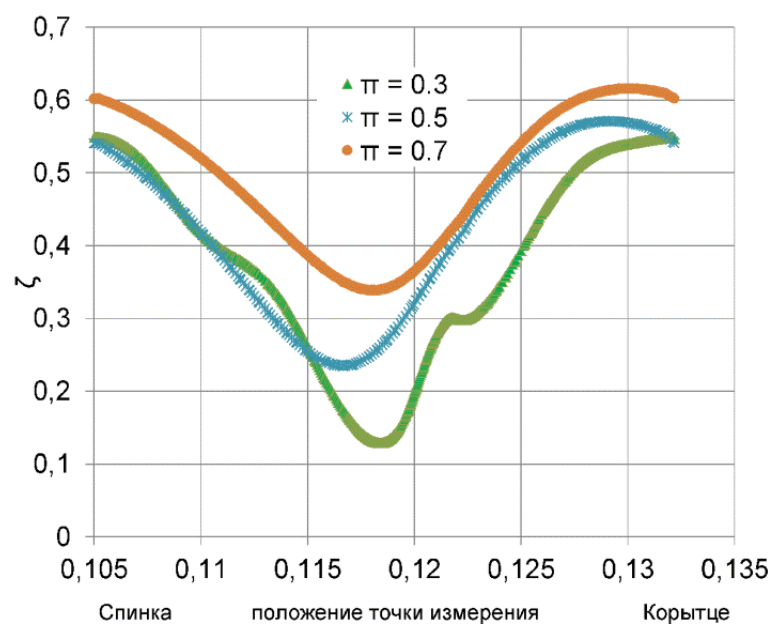

Рис. 10. Распределение коэффициентов потери кинетической энергии вдоль фронта решетки при $\pi=0,3 ; 0,5 ; 0,7$ и $\delta=0,3$

На рисунке 11 видно, что при уменьшении относительного перепада давлений на решетке уменьшается область вихревого течения и соответственно увеличивается ядро потока. С учетом ранее сказанного к рис. 11 можно сделать вывод, что уменьшение вихревой зоны и увеличение ядра потока приводит к уменьшению потерь кинетической энергии в решетке.

\section{Заключение}

По результатам проведенной работы можно сделать следующие выводы:

- дросселированние потока, проходящего через поворотную диафрагму соплового аппарата, начинает происходить при значениях отношений ширины канала на входе к горлу решетки больше единицы;

- структура потока в межлопаточном канале, соплового аппарата при малых степенях открытия, разделена на две части: сверхзвуковое ядро у корытца лопатки и дозвуковую, вихревую зону у спинки лопатки;

- сверхзвуковое ядро потока при определенных значениях относительного перепада давлений на решетке (или величины расхода воздуха через решетку) разделяется ударными фронтами на несколько областей;

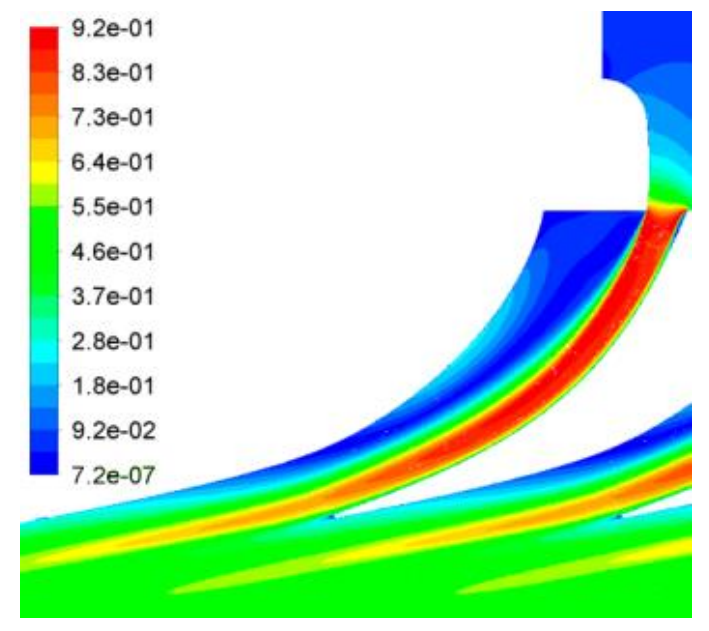

a

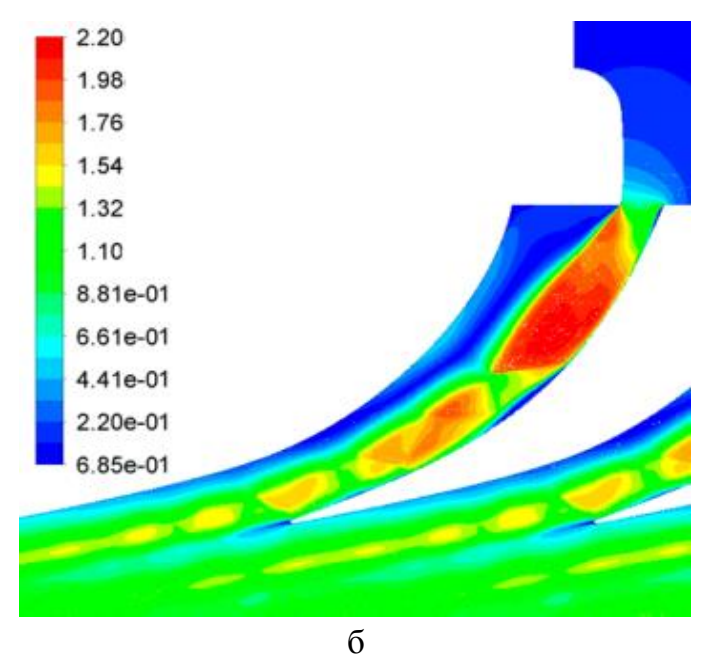

Рис. 11. Изолинии чисел Маха в межлопаточном канале при $\pi=0,7$ (а) и $\pi=0,3$ (б)

- коэффициенты потерь энергии, для малых степеней открытия, уменьшаются при уменьшении относительных перепадов давления (при увеличении скорости истечения потока из сопловой решетки);

- наибольший вклад в величину потерь кинетической энергии вносит вихревая зона в межлопаточном канале, а не волновые явления в ядре потока.

- оптимизацию проточной части соплового аппарата необходимо проводить с целью уменьшения областей с вихревым течением.

Результаты, полученные в данной работе, будут использованы для разработки метода многопараметрической оптимизации теплофикационных паровых турбин с регулируемыми отборами пара.

\section{Литература}

1. Развитие паровых турбин на сверхкритические и суперсверхкритические параметры газа [Текст] / A. A. Кондратьев, В. А. Рассохин, 
С. Ю. Олейников [и др.] // Вестник Брянского государственного технического университета. - 2017. - № 1 (54). - C. 72-82. DOI: 10.12737/24894.

2. Усатый, А. П. Создание инженерной методики оценки эффективности сопловых решеток с поворотными диафрагмами. [Текст] / А. П. Усатый, Т. А. Фам // Вестник Национального техничного университета «ХПИ». - 2018. - № 12. - С. 21 27.

3. Гурылев, В. Г. Переход сверхзвукового течения в дозвуковое в трубе с расширяюшимся начальным участком [Текст] / В. Г. Гурылев, А. К. Трифонов // Ученые записки ЦАГИ. - 1980. - Т. ХІ, № 4. C. $80-89$.

4. Пензин, В. И. Торможение сверхзвукового потока в каналах [Текст] / В.И. Пензин. - М. : Центр. аэрогидродинамич. ин-т, 2012. - 158 c.

5. Проиессы торможения сверхзвуковых течений в каналах [Текст] / О. В. Гуськов, В. И. Копченов, И. И. Липатов [и др.]. - М. : Физматлит, 2008. $-164 c$.

6. Воронецкий, А. В. Особенности течения сверхзвуковых потоков в узких изилиндрических каналах [Электронньй ресурс] / A. В. Воронецкий, С. А. Сучков, Л. А. Филимонов // Инженерный журнал: наука и инноваџии. - 2013. - Bылn. 4. - Режим docmyna: http://engjournal.ru/catalog/machin/ rocket/695.html. - 5.04.2021

7. Бененсон, Е. И. Теплофикационные паровые турбины [Текст] / Е.И. Бененсон. - М. : Энергоатомиздат, 1986. $-270 \mathrm{c}$.

8. Слабченко, О. Н. Результаты расчета течения в каналах регулирующей поворотной диафрагмы теплофикаиионной турбины [Текст] / О. Н. Слабченко, Д. В. Кирсанов // Вестник Нац. техн. ун-та "ХПИ" : сб. науч. тр. Темат. вып. : Энергетические u теплотехнические прочессы и оборудование. Харьков : НТУ "ХПИ", 2008. - № 6. - С. 73-75.

9. Дейч, М. Е. Атлас профелей решеток осевых турбин [Текст] / М. Е. Дейч, Г. А. Филипов, Л. Я. Лазарев. - М. : Машиностроение, 1965. - 96 с.

10. Ершов, С. В. Влияние сеточного разрешения на результаты расчета трехмерных течений в проточных частях турбомашин при использовании RANS моделей [Текст] / C. В. Ершов, В. А. Яковлев // Пробл. машиностроения. - 2015. - Т. 18, № 4/1. C. 18-24.

11. Глушко, Г. С. Моделирование турбулентности в сверхзвуковых струйных течениях [Электронныц ресурс] / Г. С. Глушко, И. Э. Иванов, И. А. Крюков // Физико-химическая кинетика в газовой динамике. - 2010. - T. 9. - Режим доступа: http://chemphys.edu.ru/issues/2010-9/articles/142/. 5.04.2021

12. Menter, F. R. Zonal two equation k- $\omega$ turbulence models for aerodynamic flows [Текст] / F. R. Menter // AIAA. - 1993. - No. 93-2906. - P. 1-21.

13. Курант, Р. Сверхзвуковое течение и ударные волны [Текст] / Р. Курант, К. Фридрихс. - М. :
Издательство иностранной литературы. - 1950. $427 \mathrm{c}$.

14. Носатов, В. В. Расчетно-экспериментальное исследование сверхзвукового турбулентного отрывного течения и локальной теплоотдачи в плоском канале с внезапным расширением [Текст] / B. В. Носатов, П. А. Семенёв // Вестник МГТУ им. Н. Э. Баумана Серия "Естественные науки". - 2014. - № 1. - C. 66-77.

\section{References}

1. Kondrat'ev, A. A., Rassohin, V. A., Olejnikov, S. Ju., Kondrat'ev, E. A., Osipov, A. V. Razvitie parovyh turbin na sverhkriticheskie i supersverhkriticheskie parametry gaza [Development of steam turbines for supercritical and super-critical gas-rame meters]. Vestnik Brjanskogo gosudarstvennogo tehnicheskogo universiteta [Herald of the Bryansk State Extension University], 2017, no. 1 (54), pp. 72-82. DOI: $10.12737 / 24894$.

2. Usatyj, A. P., Fam, T. A. Sozdanie inzhenernoj metodiki ocenki jeffektivnosti soplovyh reshetok $\mathrm{s}$ povorotnymi diafragmami. [Creating an engineering methodology for assessing the effectiveness of nozzle lattices with rotary diaphragms]. Vestnik Nacional'nogo tehnichnogo universiteta «HPI» [Bulletin of the National Technical University "KPI"], Kharkov, 2018, no. 12, pp. 21-27.

3. Gurylev, V. G., Trifonov, A. K. Perehod sverhzvukovogo techenija $\mathrm{v}$ dozvukovoe $\mathrm{v}$ trube s rasshirjajushhimsja nachal'nym uchastkom [Transition of supersonic flow in a dialing in a pipe with an expanding initial area]. Uchenye zapiski CAGI [Scientific Notes TsAGI], 1980, vol. XI, no. 4, pp. 80-89.

4. Penzin, V. I. Tormozhenie sverhzvukovogo potoka $v$ kanalah [Braking of supersonic current in the channels]. Moscow, Centr. ajerogidrodinamich. in-t Publ., 2012. 158 p.

5. Gus'kov, O. V., Kopchenov, V. I., Lipatov, I. I., Ostras', V. N., Staruhin, V. P. Processy tormozhenija sverhzvukovyh techenij $v$ kanalah [Processes of braking over-sound flows in channels], Moscow, Fizmatlit Publ., 2008. 164 p.

6. Voroneckij, A. V., Suchkov, S. A., Filimonov, L. A. Osobennosti techenija sverhzvukovyh potokov v uzkih cilindricheskih kanalah [Features of the flow of supersonic streams in narrow cylindrical channels]. Inzhenernyj zhurnal: nauka i innovacii [Engineering journal: Science and innovation], 2013, no. 4. Available at: http://engjournal.ru/catalog/machin/rocket/695.html. (accessed 05.04.2021).

7. Benenson, E. I. Teplofikacionnye parovye turbiny [Heat steam turbines]. Moscow, Jenergoatom-izdat Publ., 1986. 270 p.

8. Slabchenko, O. N., Kirsanov, D. V. Rezul'taty rascheta techenija $\mathrm{v}$ kanalah regulirujushhej povorotnoj diafragmy teplofikacionnoj turbiny [Results of calculating the flow in the channels of the regulating rotary diaphragm of the heat turbine]. Vestnik Nac. tehn. un-ta 
"HPI" : sb. nauch. tr. Temat. vyp. : Jenergeticheskie $i$ teplotehnicheskie processy $i$ oborudovanie [Bulletin of Nats. tehn Un-ta "KPI": Sat Scientific Tr. Temop. Vol.: Energy and heat engineering processes and equipment], Kharkov, NTU "HPI", 2008, no. 6, pp. 73-75.

9. Dejch, M. E., Filipov, G. A, Lazarev, L. Ja. Atlas profelej reshetok osevyh turbin [Atlas of chairs of lattices of axial turbines], Moscow, Mashinostroenie Publ., 1965. 96 p.

10. Ershov, S. V. Jakovlev, V. A. Vlijanie setochnogo razreshenija na rezul'taty rascheta trehmernyh techenij $\mathrm{v}$ protochnyh chastjah turbomashin pri ispol'zovanii RANS modelej [The effect of grid permission on the results of the calculation of threedimensional currents in the pro-accurate parts of the turbomachine when using RANS models]. Probl. mashinostroenija [Probl. Mechanical engineering], 2015, vol. 18 , no. $4 / 1$, pp. 18-24.

11. Glushko, G. S. Ivanov, I. Je., Krjukov, I. A. Modelirovanie turbulentnosti v sverhzvukovyh strujnyh techenijah [Physico-chemical kinetics in gas dynamics].
Fiziko-himicheskaja kinetika v gazovoj dinamike [Physico-chemical kinetics in gas dynamics], 2010, no. 9, Available at: http://chemphys.edu.ru/issues/20109/articles/142/ (accessed 05.04.2021).

12. Menter, F. R. Zonal two equation k- $\omega$ turbulence models for aerodynamic flows. AIAA, 1993, no. 93-2906, pp. 1-21.

13. Kurant, R., Fridrihs, K. Sverhzvukovoe techenie $i$ udarnye volny [Supersonic flow and shock waves] Moskow, Izdatel'stvo inostrannoj literatury Pub., 1950. $427 \mathrm{p}$.

14. Nosatov, V. V., Semenjov, P. A. Raschetnojeksperimental'noe issledovanie sverhzvukovogo turbulentnogo otryvnogo techenija i lokal'noj teplootdachi $\mathrm{v}$ ploskom kanale $\mathrm{s}$ vnezapnym rasshireniem [Calculator-experimental study of supersonic turbulent breakdown and local heat transfer in a flat channel with a sudden expansion]. Vestnik MGTU im. N.Je. Baumana Serija "Estestvennye nauki" [Bulletin MGTU them. AD Bauman series "Natural Sciences"], 2014, no. 1, pp. 66-77.

Надійшла до редакиії 26.05.2021, розглянута на редколегії 20.08.2021

\section{СТРУКТУРА ТЕЧІЇ В МІЖЛОПАТКОВОМУ КАНАЛІ СОПЛОВОГО АПАРАТУ 3 ПОВОРОТНОЮ ДІАФРАГМОЮ}

\section{О. Г. Жирков, О. П. Усатий, О. П. Авдєєва, Ю. І. Торба}

В процесі розробки методу чисельного дослідження плоского обтікання соплової решітки з поворотною діафрагмою були виконані розрахунки при різних ступенях відкриття поворотною діафрагми $\delta$ i перепадах тисків $\pi$ на решітці. В результаті розрахунків, для малих ступенів відкриття поворотною діафрагми, були отримані складні картини течії, в міжлопатковому каналі соплового апарату. У статті наведено деякі результати чисельного дослідження надзвукової течії в каналі соплового апарату при ступенях відкриття поворотної діафрагми $\delta=(0,15 \div 0,3)$. Моделювання і розрахунок течії робочого тіла виконано з використанням програмного комплексу Fluent. Проведено побудову розрахункових областей, обмежених одним міжлопатковим каналом, для різного ступеня відкриття діафрагми соплового апарату. Побудовано сітки для розрахункових областей. Проведено розрахунки для $\delta=(0,15 \div 0,3)$ і при різних ступенях перепаду тиску на решітці. В результаті виконаних розрахунків були отримані картини течії в міжлопатковому каналі і за ним, і розподіл коефіцієнтів втрати кінетичної енергії по фронту решітки при різних ступенях відкриття діафрагми на вході в соплової апарат. За результатами проведеної роботи можна зробити наступні висновки: структура потоку в міжлопатковому каналі, соплового апарату при малих ступенях відкриття, розділена на дві частини: надзвукове ядро біля коритця лопатки і дозвукову, вихрову зону біля спинки лопатки; надзвукове ядро течії при певних значеннях відносного перепаду тисків на решітці (або величини витрати повітря через решітку) розділяється ударними фронтами на кілька областей; коефіцієнти втрат енергії, для малих ступенів відкриття, зменшуються при зменшенні відносних перепадів тиску (при збільшенні швидкості витікання потоку з соплової решітки);найбільший внесок у величину втрат кінетичної енергії вносить вихрова зона в міжлопаточному каналі, а не хвильові явища в ядрі потоку; оптимізацію проточної частини соплового апарату необхідно проводити з метою зменшення областей з вихровою течією. Результати, отримані в даній роботі, будуть використані для розробки методики чисельного дослідження просторового обтікання соплових решіток з поворотними діафрагмами.

Ключові слова: поворотна діафрагма; чисельне дослідження; коефіцієнти втрат енергії; теплофікаційні турбіни; моделі турбулентності.

\section{STRUCTURE OF THE FLOW IN THE INTER-TUBE CHANNEL OF THE NOZZLE APPARATUS WITH A ROTARY DIAPHRAGM}

\section{O. Zhyrkov, O. Usaty, O. Avdieieva, Y. Torba}

In the process of developing a numerical study method of a flat flow around a snap line with a rotary diaphragm, calculations were made at various degrees of opening the rotary diaphragm $\delta$ and pressure drops on the 
grille. As a result of calculations, for small degrees, the opening of the rotary diaphragm, complex patterns of the flow were obtained, in the inter-tube channel of the nozzle apparatus. The article presents some results of a numerical study of the supersonic flow in the channel of the nozzle apparatus with the degree of opening the rotary diaphragm $\delta=(0.15 \div 0.3)$. Modeling and calculating the flow of the working fluid is made using the Fluent software package. The construction of the calculated areas bounded by one inter-tube channel, for varying degrees of opening the diaphragm of the nozzle apparatus. Grids are built for calculated areas. Calculations were carried out for $\delta=$ $(0.15 \div 0.3)$ and with different degrees of pressure drop on the grille. As a result of the calculations performed, the flow patterns in the inter-tube canal were obtained and behind it, and the distribution of the coefficients of the kinetic energy loss on the lattice front at various degrees of the discovery of the diaphragm at the inlet in the nozzle apparatus. According to the results of the work carried out, the following conclusions can be drawn: the structure of the stream in the inter-tube channel, the nozzle apparatus at small detection of the discovery, is divided into two parts: a supersonic core of the spawth of the blade and a dialing, the vortex zone at the back of the blade; The supersonic thread kernel at certain values of the relative pressure drop on the lattice (or the air flow values through the grid) is separated by shock fronts into several areas; The coefficients of energy loss, for small degrees of discovery, decrease with a decrease in the relative pressure drops (with an increase in the rate of expiration of the flow from the nozzle lattice); The greatest contribution to the magnitude of the loss of kinetic energy is introduced by a vortex zone in the inter-tube channel, and not wave phenomena in the core of the flow; Optimization of the flow part of the nozzle apparatus must be carried out in order to reduce areas with vortex flow. The results obtained in this work will be used to develop a methodology for a numerical study of the spatial flow around the nozzle lattices with rotary diaphragms.

Keywords: rotary diaphragm; numerical study; energy loss coefficients; heat turbines; turbulence models.

Жирков Александр Григорьевич - ведущий инженер-исследователь сектора газовой динамики экспериментально-испытательного комплекса, ГП «Ивченко-Прогресс», Запорожье, Украина.

Усатый Александр Павлович - д-р техн. наук, ст. науч. сотр., заведующий кафедры турбиностроения, Национальный технический университет «Харьковский политехнический институт», Харьков, Украина.

Авдеева Елена Петровна - канд. техн. наук, доц., доцент кафедры турбиностроения, Национальный технический университет «Харьковский политехнический институт», Харьков, Украина.

Торба Юрий Иванович - канд. техн. наук, начальник экспериментально-испытательного комплекса, ГП «Ивченко-Прогресс», Запорожье, Украина.

Oleksandr Zhyrkov - Leading Engineer-Researcher of the Gas Dynamics Sector of the Experimental Testing Complex of the SE "Ivchenko-Progress", Zaporozhye, Ukraine,

e-mail: zhirkov@i.ua, ORCID: 0000-0003-4003-6078.

Oleksandr Usaty - Doctor of Technical Sciences, Senior Researcher, Head of the Department of Turbine Construction, National Technical University "Kharkov Polytechnic Institute", Kharkov, Ukraine, e-mail: alpaus@ukr.net, ORCID: https://orcid.org/0000-0002-8568-5007.

Olena Avdieieva - Candidate of Technical Sciences, Associate Professor, Associate Professor of the Department of Turbine Engineering, National Technical University "Kharkov Polytechnic Institute", Kharkov, Ukraine, e-mail: Olena.Avdieieva @ khpi.edu.ua, ORCID: 0000-0002-9358-4265.

Yuriy Torba - Candidate of Technical Sciences, Head of the Experimental and Testing Complex of the SE "Ivchenko-Progress", Zaporozhye, Ukraine, e-mail: torba.yuriy@gmail.com, ORCID: 0000-0001-8470-9049. 